\title{
POLITIKK
}

SKANDINAVISK TIDSSKRIFT

FOR INTERNASJONALE STUDIER

Årgang 75, Nummer 3/4, side 230-236, 2017, ISSN 1891-1757, www.tidsskriftet-ip.no, Publisert mars 2018

\author{
Fokus: Diplomatiminister BRende
}

\section{Engasjementspolitikk på autopilot: Fredsbygging, fredsbevaring og fredsmegling under Børge Brende}

\author{
Benjamin de Carvalho og Morten Skumsrud Andersen ${ }^{1}$ \\ NUPI
}

FN er og har lenge vært en grunnpilar i utenrikspolitikken ført av fredsnasjonen Norge, supplert - og delvis finansiert - gjennom bistandspolitikken. Der egeninteressen ikke rår, dvs. der uegennytten er i førersetet, er det verdiene som styrer kursen. Utenriksminister etter utenriksminister har holdt fast ved «FN-sporet» som rettesnor i utenrikspolitiske saker, men også fortolket dette sporet og bidratt til å endre FNs politikk. Til tross for at enkelte kommentatorer har beklaget at Norge ser ut til å følge «FN-sporet» blindt (Andresen 2011), har Norge flere ganger bidratt til å endre FNs politikk og tilnærming. Avhengig av politikkområde har Norge innen flere arenaer påberopt seg talerett, og fått politisk gjennomslag i internasjonale fora. Et slikt politikkområde er engasjementspoltikken - her bredt definert som det internasjonale engasjementet med fredsbygging og bistand. Gang på gang har Norge søkt innflytelse utover sin begrensede størrelse hva gjelder FNs fredsbevarende operasjoner (de Carvalho \& Lie 2015), og gjennom omfanget av bistanden har Norge blitt en betydelig internasjonal aktør hva gjelder å definere rammene for denne aktiviteten.

I dette essayet vil vi kort skissere hovedlinjene av norsk engasjementspolitikk under Børge Brendes periode som utenriksminister (2013-2017) ved å se på Norges engasjement i Colombia før vi retter et mer kritisk blikk på norsk FN-politikk. Da Brende tok over som utenriksminister knyttet det seg flere spørsmål til hvordan en konservativ utenrikspolitikk kom til å se ut (se Leira 2012). Nå fire år senere,

${ }^{1}$ Forfatterne takker Halvard Leira, Kristin Haugevik, Iver Neumann, samt tidsskriftets anonyme fagfelle for kommentarer til tidligere utkast. 
konkluderer vi at i engasjementspolitikken er det lite nytt å melde. Kursen Brende arvet fra sine sosialdemokratiske forgjengere har han i stor grad holdt, dog med noen endringer og mer moderat fremtoning.

I ettertid blir det hevdet at Brendes jobb i hovedsak var å normalisere forholdet til Kina. Etter at dissidenten Liu Xiaobo fikk Nobels fredspris i 2010 etter å ha blitt nominert av Brendes partifelle Jan-Tore Sanner, ble Norge isolert av Kina (se Andersen $2017 \mathrm{i}$ denne spalten). Om denne isolasjonen har vært så diplomatisk smertefull at man har vært villig til å endre kurs fra å kjempe om å være klassens beste elev til heller å sitte så stille som mulig, krever flere intervjuer og større omfang enn et slikt essay tillater, men er et område som bør utforskes videre. For det er bemerkelsesverdig hvor usynlig Norges engasjementspolitikk har blitt. Under Brende har ikke Norge vært et land som "punches above its weight» som Obama kalte Norge (og alle andre allierte småstater) flere ganger, men et land som nekter å stille til kamp. Proffboksing er blitt tillatt på hjemmebane, men i utenrikspolitikk har Norge gått tilbake flere vektklasser og utfordrer ingen på fredsarbeidet eller i menneskerettighetsspørsmål.

For under Brende har engasjementspolitikken hatt en lav profil. Fredskjempen Norge, der debatten noen år før Brende tok over som utenriksminister handlet om hvorvidt landet var en humanitær supermakt eller skulle nøye seg med betegnelsen humanitær stormakt, har vært påfallende lite synlig gjennom fredsarbeidet sitt.

Riktignok har det vært - langt fra ubetydelige - suksesser, som Norges rolle i den Colombianske fredsprosessen. Under tar vi først kort for oss denne Colombianske suksessen, før vi retter et mer kritisk blikk på Norges arbeid gjennom FNs fredsoperasjoner.

\section{Norge i Colombia}

Institusjonalisering av freds- og tillitsskapende arbeid er en viktig del av norsk utenrikspolitikk fordi det gir internasjonal status, men også fordi det substansielt demper konflikter, og blir kvitt uromomenter som kan føre til uforutsigbare effekter i det globale systemet - noe som ikke vil være i Norges interesse (Neumann 2012). Norges engasjement i den colombianske fredsprosessen passer således inn i denne trenden.

Umiddelbart etter at Juan Manuel Santos ble valgt som Colombias president i 2010, etter den mer krigshissige Álvaro Uribe, begynte han å sondere mulighetene for en fredsprosess med FARC, landets største geriljagruppe. Norge hadde i mange år opprettholdt et humanitært engasjement i Colombia, og ble en naturlig kandidat for en tilretteleggerrolle i en slik prosess. Colombia, med bistand fra Norge og Cuba, gjennomførte hemmelige forhandlinger med FARC-geriljaen i to år, før prosessen ble offentliggiort i Norge i desember 2012.

Den første tiden med hemmelige og åpne forhandlinger ble holdt under de norske utenriksministrene Jonas Gahr Støre og Espen Barth Eide. Børge Brende 
ble utenriksminister i oktober 2013, og ledet den norske fredsinnsatsen i havn. Mens det så klart er det norske tilretteleggerteamet på bakken, i samarbeid med UD sentralt, ambassadene, og eksterne aktører, som gjør hovedjobben, kan en utenriksminister som tilkalt "tungt skyts» gi ekstra legitimitet og tyngde ved sitt nærvær og engasjement når det trengs. Brende utviste engasjement for Colombia. Han reiste til Cuba og Colombia flere ganger, og fulgte nøye opp situasjonen ved forhandlingsbordet.

Forhandlingene var en suksess for Norges fredsdiplomati, som til en stor grad avhenger av uformelle nettverk og kontakter. Dette viser at selv etter at freds- og forsoningsarbeidet i UD har blitt institusjonalisert, fortsetter modus operandi til en stor grad å være uformelt og nettverksbasert, i symbiose med internasjonale organisasjoner og frivillig sektor. Substansielle initiativer fra Norge i fredsprosessen, for eksempel hva angår kvinner, fred og sikkerhet, og overgangsjustis, ble i hovedsak utført gjennom andre aktører, særlig fra FN systemet. Det utstrakte samarbeidet med FN og andre internasjonale institusjoner og aktører understreker hvordan Norges diplomati avhenger av og er forpliktet til det internasjonale systemet. Som sagt: endringer i systemet vil ikke være i Norges interesse.

Norges Colombia-engasjement kan derfor sies å være en suksess - ikke minst for Colombia selv. Allikevel, på tross av Norges selvbilde som fredsnasjon (Leira 2007), at Norges fredsdiplomati er internasjonalt anerkjent, og at den colombianske fredsavtalen er det største gjennombruddet på kontinentet på mange tiår - USAs normalisering med Cuba inkludert - ser det ikke ut til at Brende valgte å utheve engasjementspolitikken i Colombia som sentral for Norges interesser. Fredsprosessen i Colombia nevnes knapt i Brendes utenrikspolitiske redegjørelser for Stortinget. Der er det heller normalisering av Norges politiske og diplomatiske relasjoner med Kina som trekkes frem.

Mens Norge samarbeidet med FN organer om utvikling og fredsskapende arbeid i Colombia, er det allikevel Norges arbeid gjennom FNs fredsoperasjoner som på mange måter har vært Norges varemerke. Det er grunner til å anta at dette varemerket har blitt svekket i Brendes periode.

\section{FNs fredsoperasjoner}

Fra mer vellykkede initiativer som FNs sikkerhetsrådsresolusjon 1325 om kvinner i konflikt i 2000 (se Solhjell et al. 2012; de Carvalho \& Schia 2009) og støtte til arbeidet med beskyttelse av sivile (se de Carvalho \& Lie 2011) til initiativer som har hatt mindre giennomslag som for eksempel «Integrated Missions» har Norge søkt å markere seg og forme måten $\mathrm{FN}$ utøver sitt begrensede mandat på hva gjelder internasjonal fred og sikkerhet. Dette sporet har også vært det Brende har fulgt.

Der Norge tidligere har søkt å forme internasjonale organisasjonens politikk, har Brende i stor grad fulgt den allerede opptråkkete stien. Kursen ble staket ut for ham lenge før han tok jobben, og denne jobben har for Brende i stor grad handlet om å 
holde stø kurs. Der Norges måte å drive fredsarbeid på tidligere har blitt beskrevet som langt fra beskjeden (Leira 2015), har dette politikkområdet blitt viet begrenset oppmerksomhet under Brende. Det er ikke dermed sagt at Brende har gjort en dårlig jobb, men heller at Norges FN-politikk under Brende ikke har vært et område der man i særlig grad har sett eller forventet sterke kursendringer eller initiativ.

Kanskje symptomatisk er det at denne delen av politikken, som i stor grad definerte Støres periode som utenriksminister (2005-2012), og som ei heller er fremmed for hans etterfølger Espen Barth Eide (2012-2013), ikke var blant de politikkområdene Brende selv trakk frem da hans periode som utenriksminister skulle oppsummeres - suksesser til tross. Det har for eksempel lenge vært en viktig prioritet for Norge å bidra til FNs fredsoperasjoner ikke bare med finansiering, sivile og politieksperter, men også med militære styrker. Til tross for en viss suksess da det norske feltsykehuset ble sendt til Tsjad i 2009 som en del av FNoperasjonen i Tsjad (MINURCAT) (se Solhjell et al. 2011; Karlsrud \& Solhjell 2012) var fiaskoen etter forsøket med å sende styrker til FN-operasjonen i Sudan (UNMIS) i 2008 i stor grad det som definerte Norges forsøk på å delta med styrker "på bakken" (se Lie \& de Carvalho 2010). At Norge under Brende ble del av FN-operasjonen i Mali (MINUSMA) med både tropper og transportfly (fra 2016) må ses på som en suksess for et land som etter mye talk lenge har ønsket å walk the walk. For selv om Norges bidrag er lite, er det lang fra ubetydelig. Riktignok utgjør Norges militære bidrag kun en fjerdedel av Sveriges, men Norge bidrar med like mange styrker som Canada og USA, og nesten like mange som Danmark. ${ }^{2}$ Det er heller ikke bare absolutte tall som teller her. Norge vil aldri kunne konkurrere med Etiopia, Bangladesh, India, Pakistan, eller Rwanda om å bidra med flest styrker - disse landene bidrar alle med hundre ganger flere styrker enn Norge. Det er også begrenset hvor mye det ville slått ut internasjonalt hva status angår om Norge hadde ønsket eller evnet å stille med flere internasjonale styrker. Når det gjelder deltagelse med militærstyrker i fredsoperasjoner handler det for Norge i stor grad om å kunne tilbakevise påstander om at landet kun er villig til å delta med finansiering, nye konsepter og formaninger i utviklingen av politikken rundt fredsbevarende operasjoner, men ikke villige til å ofre soldater "på bakken». Selv om bidraget til MINUSMA er beskjedent, er dette en viktig milepæl for Norge.

Men det gjenstår å se hvorvidt denne satsingen er et uttrykk for et ønske om å delta mer aktivt innenfor fredsbevaring, eller for en mer interessebasert politikk. Under Støre ble dette skillet delvis visket ut, da argumentet om at verdier var Norges interesser ble fremført gang på gang (se Andresen 2013). Spørsmålet man kan stille seg om fredspolitikken under Brende er om Norges interesser har blitt definerende for landets verdier. Som Karlsrud \& Osland (2017) påpeker,

${ }^{2}$ Disse tallene endrer seg over tid. Bidragene ble undersøkt 30.11.2017, https://en.wikipedia.org/ wiki/List_of_countries_by_number_of_UN_peacekeepers 
var Norges militære deltagelse i Mali-operasjonen ikke kun et uttrykk for Norges ønske om å bidra til fredsbygging:

The current conservative government, composed of the Conservative Party and the Progress Party, decided to scale up contributions, apparently due to the US initiative that resulted in a peacekeeping summit in September 2015. At the summit, Norway announced that it was replacing the contribution of analysts to the MINUSMA ASIFU with a C-130 military transport aircraft in 2016, and was considering providing combat engineers with counter-IED capability in 2017 [...] (Karlsrud \& Osland 2016)

Som de påpeker, var dette en viktig utvikling, spesielt gitt Fremskrittspartiets tidligere motstand mot engasjementspolitikken:

for the first time ever, the right-wing Progress Party argued for UN engagement, due to what it perceives as a connection between radical Islam and Norwegian security. It is likely that future UN peacekeeping missions will be deployed in countries more directly related to Norwegian security interests, such as Libya and Syria, which are linked to challenges regarding migration, violent extremism and terrorism. A significant factor is also Norway's expressed intention to run for a non-permanent seat in the Security Council for 2020-22. In the run-up, it is likely that Norway will increase its troop contribution to UN peace operations (Karlsrud \& Osland 2016)

At Norge under Brende endelig har klart å øke sitt militære bidrag til FN operasjoner er viktig, selv om det ikke nødvendigvis er et uttrykk for økt internasjonalt engasjement. At bidraget er mer et uttrykk for at man ønsker å høste fruktene av et slik engasjement enn at engasjementspolitikken selv er drivkraften gjør ikke bidraget mindre betydningsfullt. Men det bekrefter inntrykket om at engasjementspolitikken ikke har vært like viktig for Brende som den var for hans forgjengere.

\section{Tilbake til interessepolitikken?}

Engasjementspolitikken har vært mindre synlig og mindre prioritert under Brende enn under hans forgjengere. Inntrykket man sitter igjen med er at mye har gått på autopilot. Når det er sagt er ikke fredsnasjonen Norge den eneste måten Norge kan markere seg statusmessig internasjonalt. Men det har vært en viktig grunnpilar i utenrikspolitikken, og det å fortsette uten å markere dette engasjementet mer vil fort kunne medføre et behov for å omdefinere landets rolle i verden. Om det var på grunn av Kina, samarbeidspartnere i regjering, eller mangel på personlig interesse for dette politikkområdet fra utenriksministeren selv skal vi ikke spekulere i her, men det som er sikkert er at på dette feltet har Norge mer å tape enn å vinne ved å la autopiloten fortsette å styre. 
Når det er sagt har nok ikke Norge tapt altfor mye ennå. Der fredsbygging og utviklingspolitikk var viktige områder for å bygge Norges prestisje (Wohlforth et al. 2018), har Norges stillegang til tross for fortsatt engasjement ennå ikke latt seg merke så kraftig at det har medført et merkbart statusfall. Men når Norge skal fremme menneskerettigheter i ulike internasjonale fora, og dersom man går tilbake til en mer aktiv markedsføring av fredsnasjonen Norge internasjonalt, blir det interessant å se hvordan balansegangen mellom å ikke kritisere Kina til enhver pris og et aktivt, vokalt og synlig fredsengasjement kommer til å bli.

Det er ikke dermed sagt at en retur til Støres vokale engasjementspolitikk er den eneste måten for Norge å markere seg. Utenrikspolitikken under Støre ble som mange kommentatorer mente nesten ensbetydende med engasjementspolitikken (Andresen 2013). Støres "touring circus» med Refleksprosjektet var også velegnet til å skape mye blest rundt engasjementspolitikken, men det er usikkert hvor mye av dette som ble lagt merke til utenfor landets grenser (se de Carvalho 2013). I så måte er det ikke gitt at Norge har opplevd et altfor stort statusfall under Brende. Men man kommer uansett ikke unna at engasjementspolitikken var gjenstand for en betraktelig bredere og grundigere refleksjon under Støre, noe som også bidro til å synliggiøre dens plass i norsk utenrikspolitikk. Der den figurerte sentralt i Støres stortingsmelding Interesser, ansvar og muligheter (Utenriksdepartementet 2009), ble den viet noen knappe sider i Brendes Veivalg (Utenriksdepartementet 2017). Brendes stortingsmelding er i så måte symptomatisk for måten engasjementspolitikken har vært drevet de siste fire årene. Han fulgte den kursen som på forhånd var staket ut på en diskré måte, la merke til og påpekte at det fantes alternative kurser eller «veivalg», men svingte ikke inn på mange av dem. Brendes ledelse har tidvis vært god, og han kan vise til flere suksesser. Men til tross for en stortingsmelding har engasjementspolitikken under Brende manglet en klar visjon og minnet mer om forvaltning.

\section{Referanser}

Andresen, Nils August (2011) «FN-sporet en avsporing», Minerva. Tilgjengelig på: https://www.minervanett. no/fn-sporet-en-avsporing/

Andresen, Nils August (2013) «Verdiløse interesser» Internasjonal Politikk 71(3), 432-440.

de Carvalho, Benjamin (2013) «Engasjement som norsk nasjonal interesse», Internasjonal Politikk, 71(3), 407-420.

de Carvalho, Benjamin \& Jon Harald Sande Lie (2011) «Chronicle of a Frustration Foretold? The Implementation of a Broad Protection Agenda in the United Nations", Fournal of International Peacekeeping, 15 (3-4), 341-362.

de Carvalho, Benjamin \& Jon Harald Sande Lie (2015) «A great power performance: Norway, Status and the Policy of Involvement» i Benjamin de Carvalho \& Iver B. Neumann (red.) Small State Status Seeking: Norway's Quest for International Standing. London: Routledge (56-72).

Karlsrud, John \& Randi Solhjell (2012) «Gender-sensitive protection and the responsibility to prevent: lessons from Chad", Global Responsibility to Protect, 4(2), 223-240.

Karlsrud, John \& Kari M. Osland (2016) «Between self-interest and solidarity: Norway's return to UN peacekeeping?», International Peacekeeping, 23(5): 784-803.

Leira, Halvard (red.) (2007) Norske selvbilder og norsk utenrikspolitikk. Oslo: NUPI.

Leira, Halvard (2012) «Drømmen om en ny utenrikspolitikk», Nytt norsk tidsskrift, 29(4), 382-393. 


\section{Benjamin de Carvalho og Morten Skumsrud Andersen}

Leira, Halvard (2015) «The formative years: Norway as an obsessive status-seeker» i Benjamin de Carvalho \& Iver B. Neumann (red.) Small State Status Seeking: Norway's Quest for International Standing. London: Routledge (22-41).

Leira, Halvard \& Nina Græger (2017) «Diplomatiminister Brende» Internasjonal Politikk 75 (3-4).

Lie, Jon Harald Sande \& Benjamin de Carvalho (2010) «Between culture and concept: The protection of civilians in Sudan (UNMIS)", fournal of International Peacekeeping, 14 (1-2), 60-85.

Solhjell, Randi, Benjamin de Carvalho \& Jon Harald Sande Lie (2011) Somewhere to Turn? MINURCAT and the Protection of Civilians in Eastern Chad and Darfur. Oslo: NUPI.

Solhjell, Randi, Marcela Donadio, Ancil Adrian-Paul, Niels Nagelhus Schia \& Renata Giannini (2012) Turning UNSC Resolution 1325 into operational practice: A cross-country study on implementing Resolution 1325 in peacekeeping and military operations. Oslo: NUPI.

Utenriksdepartementet (2009) St.meld. nr. 15 (2008-2009) Interesser, ansvar og muligheter - Hovedlinjer $i$ norsk utenrikspolitikk. Tilgjengelig på: https:/www.regjeringen.no/no/dokumenter/stmeld-nr-15-2008-2009-/ id548673/

Utenriksdepartementet (2017) Meld. St. 36 (2016-2017),Veivalg i norsk utenriks- og sikkerhetspolitikk. Tilgjengelig på: https://www.regjeringen.no/no/dokumenter/meld.-st.-36-20162017/id2549828/

Wohlforth, William, Benjamin de Carvalho, Halvard Leira \& Iver B. Neumann (2018, forthcoming) «Moral Authority and Status in International Relations: Good States and the Social Dimension of Status-Seeking", Review of International Studies 